\title{
A Gestão da Informação sob a abordagem da Ecologia: possibilidades à competência em informação
}

\author{
Elizabeth Coelho Rosa e Silva \\ Mestre; Universidade Federal de Santa Catarina; elizabeth.coelho@ufsc.br \\ Elizete Vieira Vitorino \\ Doutora; Universidade Federal de Santa Catarina; elizete.vitorino@ufsc.br
}

\begin{abstract}
Resumo: A existência das organizações atuais ocorre em um ambiente de interrelações em constante estado de transformação. Nesse contexto, o valor da informação é determinante para as organizações preverem, compreenderem e responderem às transformações ambientais. $\mathrm{O}$ trabalho apresenta a Gestão da Informação sob a abordagem da Ecologia da Informação, caracterizando-se como pesquisa bibliográfica, permitindo a recuperação do conhecimento científico acumulado sobre Gestão da Informação, Ecologia da Informação e competência em informação, a partir de material elaborado principalmente em livros e artigos científicos. Examina as relações entre competência em informação e Ecologia da Informação, concernentes à inovação conceitual na Ciência da Informação. Os resultados apontam para a integração dos diversos componentes informacionais, o que denota a necessidade em assimilar a informação sob uma perspectiva menos tecnológica e mais crítica e reflexiva, colocando pessoas no centro do gerenciamento informacional, com vistas ao desenvolvimento da competência em informação.
\end{abstract}

Palavras-chave: Gestão da Informação. Ecologia da Informação. Competência em Informação.

\section{Introdução}

A existência das organizações atuais ocorre em um ambiente de inter-relações em constante estado de transformação. A informação, neste ambiente, representa um determinante valor organizacional, no sentido de prever, compreender e responder às transformações ambientais (BEAL, 2004). Para McGee e Prusak (1994), a informação consiste em dados coletados, organizados e orientados, aos quais são atribuídos significados e contextos; e conhecimento, para Davenport 
(1998, p. 19) “[...] é a informação mais valiosa e, consequentemente, mais difícil de gerenciar.”.

Rezende e Abreu (2011) discorrem sobre as características da organização tradicional e da nova organização baseada na informação. As características das organizações atuais, mais voltadas e atentas ao fluxo da informação e do conhecimento, levam à necessidade da gestão diária da informação. Davenport (1998) propõe uma perspectiva holística, usando o termo Ecologia da Informação, que compreende três ambientes: o informacional, o organizacional e o ambiente externo.

Nesse trabalho, pretende-se descrever os componentes do ambiente informacional de organizações: princípios informacionais, política informacional, comportamento e cultura informacional, equipe informacional, processos informacionais e arquitetura informacional; descrever os componentes do ambiente externo às organizações, ambiente social, ambiente tecnológico e ambiente informacional; e destacar as possibilidades de se desenvolver a competência em informação nesses ambientes.

\section{Aspectos metodológicos}

A presente pesquisa caracteriza-se, quanto à forma de abordagem, como pesquisa qualitativa. Para Godoy (1995), o pesquisador constitui o instrumento fundamental da pesquisa, analisando e refletindo sobre os dados obtidos, no campo ou no conhecimento registrado. A interação com as fontes, a análise destas, bem como a reflexão realizada quanto à Gestão da Informação sob a abordagem da Ecologia da Informação e a competência em informação possibilitaram compreender aspectos significativos das relações entre esses temas.

Segundo Gil (1991), é possível classificar uma pesquisa como exploratória quando o seu objetivo é obter maior familiaridade com um tema ainda pouco estudado ou conhecido. Assim, o estudo aqui realizado caracterizase como uma pesquisa exploratória e, quanto aos procedimentos técnicos, trata- 
se de uma pesquisa bibliográfica, realizada a partir de material elaborado principalmente em livros e em artigos científicos.

Por intermédio da pesquisa bibliográfica, o referencial conceitual sobre a Gestão da Informação, a Ecologia da Informação e a competência em informação foi construído na perspectiva de uma reflexão sobre as relações entre estas, no que diz respeito à inovação conceitual na Ciência da Informação. Cabe também ressaltar que este estudo apresenta uma inovação conceitual e um novo olhar para a pesquisa ampla e aplicada realizada sobre o tema Gestão da Informação, cujos resultados podem ser vistos em Silva (2012).

\section{Gestão da Informação: algumas considerações}

Em termos de área de estudo, a Gestão da Informação refere-se às atividades relacionadas à informação, fazendo intersecção com as áreas de Ciência da Informação, Sistemas de Informação, Tecnologia da Informação e Gestão do Conhecimento. A Gestão da Informação é constituída por diversos processos, na intenção de construir a ligação entre a gestão estratégica e a aplicação da tecnologia da informação nas organizações, constatando qual informação interessa, para, a seguir, definir processos, identificar fontes e modelar sistemas (GEWANDSZNAJDER, 2005).

Passos de Oliveira (2010), com base no processo decisório organizacional, divide a Gestão da Informação em três níveis: estratégico, tático e operacional. Segundo essa classificação, a especificidade das informações aumenta na base da pirâmide, onde é necessário resolver questões operacionais, enquanto no topo as decisões estratégicas exigem informações que envolvem as relações da organização como um todo.

Para Amaral (1994, p. 27), a Gestão da Informação tem por objetivo sustentar uma visão global dos dados organizacionais, satisfazendo as necessidades de informação, “[...] por intermédio da determinação e operacionalização de quais, onde, quando e como os dados e informações devem estar presentes na vida da organização.”. Choo (2003) trata da Gestão da Informação como um ciclo de atividades informacionais inter-relacionadas em 
uma perspectiva baseada em processos que compreendem a tecnologia da informação, os recursos informacionais, a política informacional e o processo informacional. Para o autor, a Gestão da Informação “[...] busca explorar os recursos de informação para que a organização seja capaz de se adaptar às mudanças do ambiente interno e externo." (CHOO, 2003, p. 40). Perspectiva semelhante é estudada na Ciência da Informação, e, em específico, na competência em informação (URIBE TIRADO, 2011).

$\mathrm{Na}$ perspectiva das ações de informação e seus desdobramentos em sistemas, serviços e produtos, para González de Gómez (1999, p. 68), a Gestão da Informação envolve o "[...] planejamento, instrumentalização, atribuição de recursos e competências, acompanhamento e avaliação.”. Para a autora, a gestão estabelece a mediação entre as políticas de informação e a ação dos atores sociais envolvidos, pela disponibilização ou omissão de informação.

Do intuito de planejamento e acompanhamento, do crescente volume de informação à disposição, aliados ao desejo de controle, emerge, nas organizações, a necessidade da Gestão da Informação, a qual, desde o início, pode compreender quatro diferentes abordagens de controle que correspondem a quatro modalidades ou fluxos de informação: informação não estruturada, capital intelectual ou conhecimento, informação estruturada em papel, e informação estruturada em computadores (DAVENPORT, 1998). Ainda, segundo Davenport (1998), essas abordagens apresentam problemas em comum: usam informações que se sobrepõem a outros modelos, adotam estilos gerenciais inadequados e ignoram os fatores comportamental e social no uso da informação.

Um novo foco ao gerenciamento informacional é proposto por Davenport (1998), o Gerenciamento Ecológico da Informação. A seguir, será apresentado e caracterizado o modelo.

\section{Ecologia da Informação: modelo de Davenport (1998)}

Segundo Davenport (1998), a utilização da expressão ecologia como metáfora, que ocorre no final da década de 50, vem da experiência dos estrategistas e 
estudiosos das organizações, que consideram que a administração e a estratégia organizacionais são processos imprevisíveis e inadiáveis, determinados por fatores comportamentais, como caprichos políticos, motivações conflitantes e percepções imperfeitas. O termo Ecologia da Informação provoca reações variadas, no entanto, o autor utiliza metáforas por considerá-las poderosas para induzir comportamentos e ajudar a formar uma nova visão organizacional.

Davenport (1998, p. 21) descreve a Ecologia da Informação como “[...] administração holística da informação ou administração informacional centrada no ser humano.”. A abordagem ecológica ou holística da informação vem contrariando a visão que permanece em espaços e comportamentos organizacionais, em que o avanço da tecnologia vem privilegiando os aspectos do domínio tecnológico em prejuízo aos objetivos principais da informação que são informar, transferir conhecimento e construir a história.

A base do modelo da Ecologia da Informação é o oposto da abordagem de máquina: o foco, em vez de ser na tecnologia, é na maneira como as pessoas criam, distribuem, compreendem e usam a informação. Administradores adeptos à abordagem ecológica acreditam que a informação não é facilmente arquivada em computadores, não é constituída apenas de dados e que, quanto mais complexo o modelo da informação, menor será sua utilidade. A informação pode ter muitos significados em uma organização e a tecnologia é apenas um dos componentes do ambiente de informação, não se apresentando, frequentemente, como meio adequado para operar transformações.

A essência da abordagem é colocar o homem no centro do mundo da informação e a tecnologia a serviço dele, e não no seu comando. A ênfase primária está no uso adequado de uma quantidade pequena de informação e no seu planejamento ecológico, permitindo evolução e interpretação; colocando a responsabilidade da informação a quem precisa e faz uso dela, eliminando, assim, seu controle central. Nesse sentido, o papel dos ecologistas da informação passa do controle para a mobilização.

A Ecologia da Informação, além de exigir um modo holístico de pensar, tem quatro atributos-chave, ou seja, fundamentos teóricos do conceito de Ecologia da Informação, assim definidos: integração dos diversos tipos de 
informação, reconhecimento de transformações evolutivas, ênfase na observação e na descrição, e ênfase no comportamento pessoal e informacional.

Davenport (1998) propõe para a Gestão da Informação uma perspectiva holística, usando o termo Ecologia da Informação, que compreende todo o ambiente informacional. Em qualquer ecologia informacional existem três ambientes: o ambiente informacional, o organizacional e o ambiente externo. $\mathrm{O}$ autor concentra-se

[...] principalmente no ambiente informacional, mas este está arraigado no ambiente mais amplo que o envolve, o organizacional, e ambos são afetados pelo ambiente externo, o mercado. Na prática, esses ambientes se sobrepõem e têm limites indistintos. É por esse motivo que as iniciativas informacionais podem envolver os três, estejam os administradores cientes ou não do elo que os liga. (DAVENPORT, 1998, p. 50).

A ênfase na observação e descrição do ambiente informacional é atributo fundamental da Ecologia da Informação e, para o gerenciamento ecológico da informação, é primordial conhecer o cenário em que a informação é utilizada. Assim como noutras instâncias do ambiente externo mais amplo, constata-se nas organizações uma preocupação tanto com seu contexto interno quanto com as relações que se estabelecem com o ambiente externo. Essa preocupação tem origem nos desafios contemporâneos para a construção ou para o reordenamento das sociedades, superando desigualdades (informacionais, por exemplo) nas relações de trabalho e destas com o mundo do trabalho. Rios (2008) orienta que é preciso levar em consideração o contexto no qual o objeto (neste caso, a informação) se insere e estudar os elementos que o determinam, bem como os diversos ângulos sob os quais se apresenta.

O cenário informacional, sob esta linha de raciocínio, significa a descrição de como os indivíduos numa organização, influenciada pelo ambiente externo, utilizam a informação e o que pensam sobre ela. Envolvem-se neste cenário componentes que se interconectam. $\mathrm{O}$ ambiente informacional compreende os seguintes componentes: estratégia da informação, política da informação, comportamento e cultura em relação à informação, equipe da informação, processos de gerenciamento da informação e arquitetura da informação. Por sua vez, o ambiente organizacional abrange tais componentes: 
situação administrativa, disposição do espaço físico e investimento em tecnologia. Já o ambiente externo contém os componentes mercados de negócios, mercados de informação e mercados de tecnologia. Esses componentes informacionais estão indicados no modelo ecológico para o gerenciamento da informação proposto por Davenport, conforme representado na Figura 1.

Figura 1 - Modelo ecológico para o gerenciamento da informação

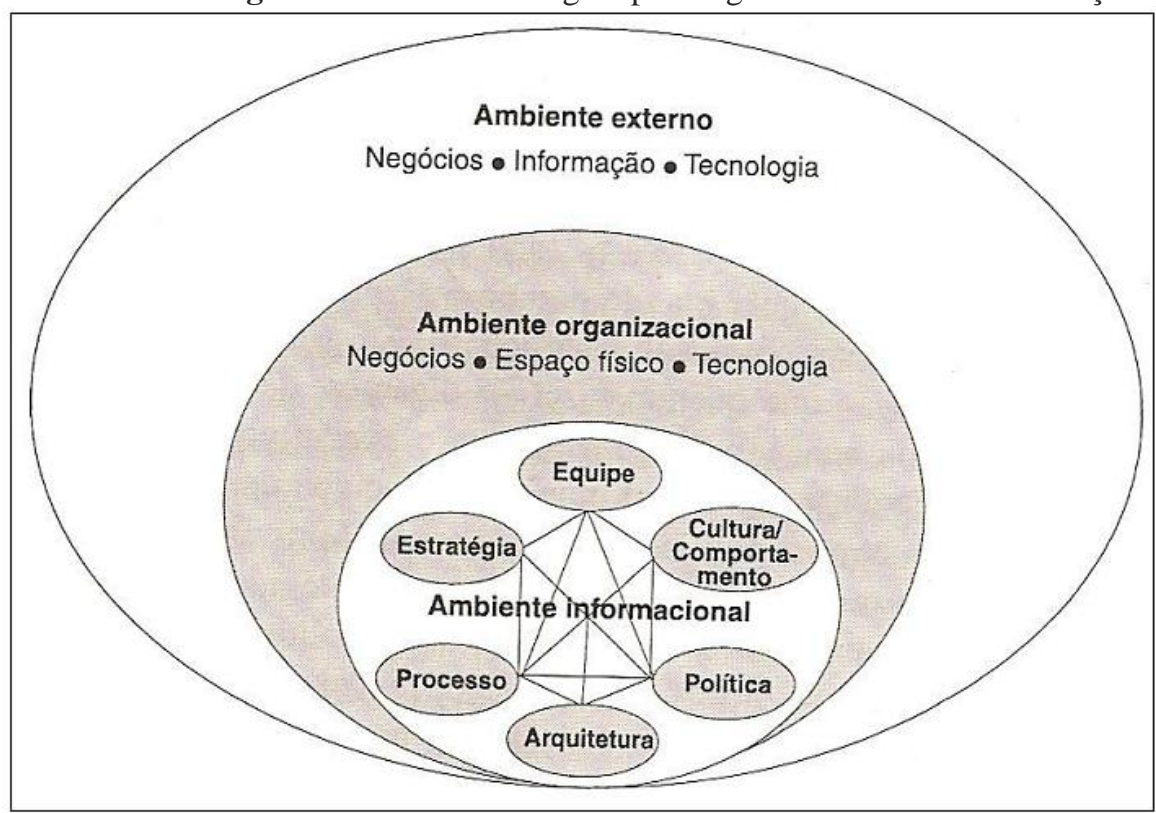

Fonte: Davenport (1998).

Tendo em vista a complexidade do modelo proposto por Davenport, das variáveis nele existentes e dos propósitos deste trabalho, ou seja, examinar as relações existentes entre a competência em informação e a Ecologia da Informação, a ênfase aqui é dada ao ambiente informacional. $\mathrm{O}$ ambiente informacional é influenciado pelos ambientes mais amplos que o envolvem, o organizacional e o externo. Ambiente informacional é o núcleo da abordagem ecológica e compreende os seis componentes mais significativos desta: estratégia da informação, política da informação, cultura e comportamento em relação à informação, equipe da informação, processos de gerenciamento da informação e arquitetura da informação: 
a) estratégia da informação: constitui-se dos objetivos informacionais básicos que servem de guia para a ação. Significa a possibilidade de fazer escolhas e a maneira como a informação poderá ajudar a organização a alcançar seus objetivos (DAVENPORT, 1998). Em vez de focalizar em um conteúdo específico de informação, algumas organizações preferem focalizar e compartilhar informações comuns. É necessário que este foco esteja implícito e definido expressamente como elemento da estratégia. Esta não é a opção mais fácil, pois é difícil criar e manter informações comuns, mas é habitual nas organizações, para facilitar a comunicação, a troca de informações comuns entre as divisões, as funções e os processos administrativos;

b) política da informação: para Davenport (1998, p. 52), “[...] envolve o poder proporcionado pela informação e as responsabilidades da direção em seu gerenciamento e uso.”. A informação passa a ser encarada como uma fonte de poder. Freire (2008), no seu estudo sobre políticas públicas de informação, correlaciona os conceitos de política e informação e conceitua políticas de informação no sentido da ordem e regulação;

c) cultura e comportamento em relação à informação: para Davenport (1998, p. 110), comportamento informacional refere-se ao modo como os indivíduos lidam com a informação, e entende por cultura informacional “[...] o padrão de comportamentos e atitudes que expressam a orientação informacional de uma empresa.”. A cultura e o comportamento informacional são os componentes da ecologia informacional mais resistentes à transformação. Pode-se considerar um conjunto de valores que, na prática, funcionam como lei que regula o ambiente organizacional;

d) equipe da informação: é composta pelos diferentes tipos de pessoas que fornecem e interpretam as informações. Neste sentido, Sordi (2003) reforça que a equipe informacional deve abranger as pessoas que possam agregar valor à informação, não se limitando aos profissionais de tecnologia da informação; 
e) processo de gerenciamento da informação: demonstra como o trabalho é feito. Para Davenport (1998, p. 173) os processos informacionais devem ser definidos para qualquer atividade que envolva informação, assim o processo de gerenciamento da informação é um "[...] conjunto estruturado de atividades que incluem o modo como as empresas obtêm, distribuem e usam a informação e o conhecimento.”. Na abordagem ecológica, o aperfeiçoamento dos processos informacionais envolve o reconhecimento da desordem, instabilidade e complexidade do ambiente externo, dos locais de trabalho e, especialmente, do comportamento humano, valorizando o desempenho das pessoas e o uso de fatores múltiplos inter-relacionados. Uma orientação ecológica voltada ao processo leva à cooperação interfuncional e melhora a localização da informação;

f) arquitetura da informação: este componente é utilizado na área de sistemas de informação, com o objetivo de criar um mapa abrangente dos dados organizacionais e, em seguida, construir um sistema baseado nesse mapa. Com a ampliação crescente dos sistemas automatizados de informação, o foco passa para a resolução dos problemas causados pelos sistemas, e não mais à criação de mapas informacionais. Ramos, Alcantara e Moresi (2011) consideram que a arquitetura da informação abrange a informação em formas e tamanhos diversos, como web sites, documentos, softwares, aplicativos e imagens, englobando, também, os metadados.

Na prática, a arquitetura da informação faz a acomodação dos recursos existentes na organização às necessidades da informação. Organizando os dados em formatos, categorias e relações coerentes, a arquitetura da informação faz a comunicação entre o comportamento, os processos, a equipe da informação, bem como outros aspectos organizacionais, como métodos administrativos, estrutura e espaço físico.

As organizações não são autônomas em termos informacionais pois suas estratégias não podem se restringir à informação coletada internamente. Elas 
dependem, inclusive, de informação existente no ambiente externo onde atuam (HENRIQUE; BARBOSA, 2009). Para Davenport (1998, p. 248), as organizações podem responder ao ambiente externo por intermédio de três tipos de reação:

a) adaptar-se ao mundo exterior;

b) investigar esse mundo em busca de transformações a que deve responder;

c) moldar as condições exteriores, por meio de serviços e produtos da informação, visando a sua própria vantagem competitiva.

As organizações não são uma ilha, pois trocam informações com o ambiente externo, independentemente dos seus tamanhos, características e estruturas, interagindo com o mundo exterior: adaptando-se, investigando e moldando o mundo exterior.

Para Davenport (1998, p. 268), “[...] o sistema de informação interno deve ser flexível o bastante para estabelecer os canais, os protocolos e os conteúdos para a transferência de informação $[\ldots]$ ", seja para atendimento às regulamentações governamentais ou conexão das interfaces com consumidores e fornecedores. O intercâmbio de informação estruturada e o componente humano são insubstituíveis para que a organização se mantenha adaptável ao ambiente externo. A relação interpessoal, as reuniões, o rodízio e a escala de equipes são canais de interação que precisam ser valorizados. A investigação do ambiente externo é mais importante do que se adaptar a ele ou moldá-lo. Consiste em "[...] fazer com que uma organização se volte para fora e responda efetivamente ao que descobre [...]", defende Davenport (1998, p. 270). Para que isso ocorra de fato, o processo de investigação, com base no modelo ecológico de gerenciamento da informação, consiste nos seguintes passos: identificar as necessidades de informações externas, decidir onde procurar informação, conduzir a informação externa para dentro da organização e utilizar a informação externa. 


\section{Competência informacional: relações com a Ecologia da Informação}

Em 1965, um dos educadores mais ilustres da Austrália, Ernest Roe, professor de Educação da Universidade de Queensland, observou que, em geral, “[...] promover o uso eficiente [...]" dos recursos não era uma preocupação dos “[...] promotores do mundo informacional [...]" (BUNDY, 2004, p. 45). Segundo ele, mesmo onde havia uma preocupação ativa, lacunas significativas persistiam. Por exemplo: um diretor de uma organização pode pedir aos funcionários para que usem os recursos informacionais, pode fornecer listas sugestivas de materiais e indicar os insumos a serem utilizados na organização (BUNDY, 2004). O trabalho poderá ser realizado de forma eficaz e os resultados podem ser alcançados, mas o mesmo diretor não tem interesse em saber como seus funcionários usam os recursos que ele mesmo (o diretor) está tão interessado que eles usem, ou em saber se eles têm as habilidades necessárias para fazê-lo.

Por outro lado, outro diretor pode estar ativamente envolvido em ajudar, por assim dizer, no desenvolvimento dos funcionários de modo a serem hábeis em estratégias de busca, em todos os sentidos. Mas ainda assim é preciso considerar o que os funcionários fazem com o dado "certo" quando eles o localizam (BUNDY, 2004). Este é apenas um exemplo do uso restrito que os funcionários fazem das fontes e recursos informacionais, por desconhecerem como se dá o processo de aprendizado do mundo informacional e que nem sempre está disponível de forma adequada para os usos da organização.

A competência em informação - o termo foi usado pela primeira vez pelo bibliotecário americano Paul Zurkowski, em 1974, num relatório sobre o ambiente de serviço de informação nos Estados Unidos da América (EUA) referia-se às relações existentes entre dados e as prioridades que o país deveria dar ao fenômeno ainda não resolvido da explosão informacional (DUDZIAK, 2003, 2010; ZURKOWSKI, 1974).

Para ser competente em informação, uma pessoa deve ser capaz de reconhecer quando uma informação é necessária e deve ter a habilidade de localizar, avaliar e usar efetivamente a informação e, assim, aprende a aprender e sabe como aprender, pois sabe como o conhecimento é organizado, como 
encontrar a informação e como usá-la de modo que outras pessoas possam aprender a partir dela (ASSOCIATION OF COLLEGE \& RESEARCH LIBRARIES, 1989). Há, neste conceito, uma clara associação da competência em informação com o modelo Ecológico da Informação.

Deste modo, e a partir do que foi anunciado por Davenport (1998) sobre as características do modelo Ecológico da Informação, o Quadro 1 mostra algumas possibilidades de relações com a competência em informação.

Percebe-se que as relações existentes entre a Ecologia da Informação e a competência em informação têm razão de ser: ambas propõem o conhecimento adequado do ambiente informacional como fator de transformação e desenvolvimento humano.

Quadro 1 - Relações entre a Ecologia da Informação e a competência em informação

Ecologia da Informação

\section{Competência em informação e} Dimensões

(VITORINO; PIANTOLA, 2009; 2011)
Base do modelo da Ecologia da Informação: maneira como as pessoas criam, distribuem, compreendem e usam a informação; a administração informacional abre espaço para a transformação.

A tecnologia é apenas um dos componentes do ambiente de informação e frequentemente não se apresenta como meio adequado para operar transformações.

A informação passa a ser encarada como uma fonte de poder; diz respeito ao cidadão, estabelecendo os critérios da justiça e examinando as condições sob as quais o homem pode atingir a felicidade (o bemestar) na sociedade, em sua existência coletiva.

Refere-se ao modo como os indivíduos lidam com a informação, comportamentos e atitudes, bem como um conjunto de valores que, na prática, funcionam como lei que regula o ambiente organizacional.
Desenvolvimento da habilidade de construir sentido, cujo resultado é o aprendizado independente e o pensamento autônomo.

(Dimensão Estética)

Uma série de habilidades e conhecimentos que nos permitem encontrar, avaliar e usar a informação de que precisamos, assim como filtrar a informação de que não necessitamos (a tecnologia é um dos meios para o desenvolvimento da competência em informação no indivíduo).

\section{(Dimensão Técnica)}

Muito mais do que uma reunião de habilidades para acessar e empregar adequadamente a informação; tratase de uma ferramenta essencial na construção e manutenção de uma sociedade livre, verdadeiramente democrática, em que os indivíduos fariam escolhas mais conscientes e seriam capazes de efetivamente determinar o curso de suas vidas.

\section{(Dimensão Política)}

Mais amplamente entendida como uma "arte neoliberal", que vai desde saber como usar os computadores e acessar a informação até a reflexão crítica sobre a natureza da informação em si, sua infraestrutura técnica, e o seu contexto e impacto social, cultural e mesmo filosófico.

(Dimensão Ética)

Fonte: Elaborado pelas autoras. 
Argumentando sobre esta importante relação, Singh (2008) considera que o principal propósito da competência informacional seja o desenvolvimento da habilidade de construir sentido, cujo resultado seria o aprendizado independente e o pensamento autônomo. $\mathrm{O}$ autor enfatiza que a exploração e a análise da ecologia informacional e da diversidade sociocultural constituem-se como componentes essenciais do processo da competência informacional.

Mais recentemente, Uribe Tirado (2010), pesquisador colombiano, em suas pesquisas relacionadas com o cenário ibero-americano, fornece um conceito abrangente e, ao mesmo tempo, adequado ao complexo ambiente informacional, o qual considera uma "macrodefinição" da competência em informação. Segundo o autor, e, analisando as definições mais utilizadas na literatura (de modo a extrair tendências e inter-relações entre os conceitos, com o objetivo de servir de guia para a elaboração de atividades), a competência em informação é considerada como o processo de ensino-aprendizagem. Tal processo busca que um indivíduo e seu coletivo, empregando diferentes estratégias de ensino e ambientes de aprendizagem, desenvolvam habilidades, atitudes e conhecimento, de forma que lhes permitam, depois de identificar suas necessidades informacionais, poder localizar, selecionar, recuperar, organizar, avaliar, produzir, compartilhar e divulgar essa informação.

Ainda, para Uribe Tirado (2010), esse "poder do indivíduo" só se concretiza se houver uma postura crítica e ética, a partir de suas potencialidades (cognitivas, práticas e afetivas) e conhecimentos prévios, de acordo com os diferentes papéis e contextos que assume (desempenho de trabalho ou profissional, por exemplo) para o aprendizado ao longo da vida e para o benefício pessoal e organizacional, atendendo as demandas da sociedade da informação.

Ao que se percebe, trata-se de uma definição que mostra efetivamente uma visão "ecológica" do processo de desenvolvimento da competência em informação. Nesse sentido, já existe na literatura da área da Ciência da Informação estudos que buscam essa relação entre o modelo Ecológico da Informação e a competência em informação. Um desses estudos, o trabalho de Steinerová (2010), é apresentado a seguir. 


\section{Dimensões ecológicas da competência informacional}

Com base em análises realizadas a partir das relações entre competência em informação e Ecologia da Informação no que diz respeito à inovação conceitual na Ciência da Informação, Steinerová (2010), pesquisadora do Department of Library and Information Science da Comenius University Bratislava, Eslováquia (Europa), procura compreender o comportamento humano na busca e avaliação da informação em ambiente eletrônico. A autora propõe quatro dimensões ecológicas da competência em informação, as quais incluem a dimensão semântica (relevância), a dimensão visual (horizontes informacionais), a dimensão comportamental (estilo) e a dimensão social (comunidade, valores). Tais dimensões são derivadas das seguintes premissas:

a) a competência em informação é parte do comportamento de busca da informação e é vista como um processo holístico complexo, que é semelhante àquilo que ocorre com os organismos naturais;

b) a avaliação da relevância ecológica ocorre na medida em que se vincula o conhecimento externo e interno, as emoções e as redes sociais;

c) em ambientes digitais, é possível gerenciar a reutilização ecológica dos objetos, serviços e produtos de informação;

d) atividades epistêmicas conectam pessoas e ambientes de informação e transformam a informação em conhecimento, enquanto estados cognitivos adaptam, evoluem e mudam dentro de uma comunidade;

e) atividades de informação ecológicas são baseadas na interação de valores, ferramentas de organização e comunidades de conhecimento; e

f) a competência em informação pode ser aprimorada por meio da filtragem destas e da visualização de informações em ambiente eletrônico.

Ainda, para a autora, a competência em informação está interligada com as habilidades digitais e com a consciência ética (uso justo). As ferramentas para a satisfação da busca (conclusão da busca por informação) e otimização em sistemas de informação podem ajudar a avaliar a relevância e dar sentido às 
informações. As principais características ecológicas da competência em informação são determinadas pela adaptação e filtragem: são como um filtro, apoiando a transição da informação para o conhecimento. Nesse sentido, a autora propõe um modelo de dimensões ecológicas para a competência em informação a partir da perspectiva ecológica (STEINEROVÁ, 2010).

No modelo proposto, Steinerová (2010) esclarece que a atividade de informação pode ser configurada por modelo triangular de Engeström. A ideia de modelo triangular da atividade incorpora os aspectos socioculturais, ou seja, reflete a natureza tanto coletiva quanto colaborativa da atividade humana. Este modelo pode ser melhor visualizado no estudo disponibilizado em Heemann (2006). O modelo está composto por três componentes: homem, objetos de informação e ferramentas. Isto pode ser combinado em atividades como produção, consumo e distribuição de informação. Além das ferramentas de comunicação, um papel importante é desempenhado pela comunidade, pelos valores, pela divisão do trabalho e pela colaboração. Cognição e comunicação, adaptação e interação, relevância, satisfação e otimização são princípios fundamentais para a modelagem da competência em informação.

Um modelo de dimensões ecológicas da competência em informação (Figura 2) conecta o nível micro competência em informação (afetivo, cognitivo, senso-motor e social dos atores sociais) com nível macro do ambiente de informação.

$\mathrm{O}$ ator social desenvolve a sua competência em informação como um caminho por meio do ambiente de informação. Por esta via, ele usa um conjunto de valores (para avaliação relevância), ferramentas especiais (linguagem, ferramentas de organização do conhecimento) e atua como parte de comunidades (operado pelos padrões do grupo, valores, papéis sociais e padrões de comunicação).

A parte esquerda do modelo integra os processos intelectuais de Gestão da Informação. O lado direito do modelo retrata interconexões de fontes de informação e processos de informação. Ligações entre ambiente externo e interno são manifestadas por intermédio do uso de fontes de informação, 
tecnologias da informação, estilos de informação, avaliação de relevância e pela construção de significados.

Ambos os lados colocam a competência em informação como a transição da informação para o conhecimento.

O modelo generaliza os dados empíricos sobre comportamento, relevância e estilos de informação. As dimensões ecológicas da competência em informação representam o desenvolvimento desta metacompetência por meio de atividades e em movimentos no ambiente de informação.

Figura 2: Modelo de dimensões ecológicas da competência em informação

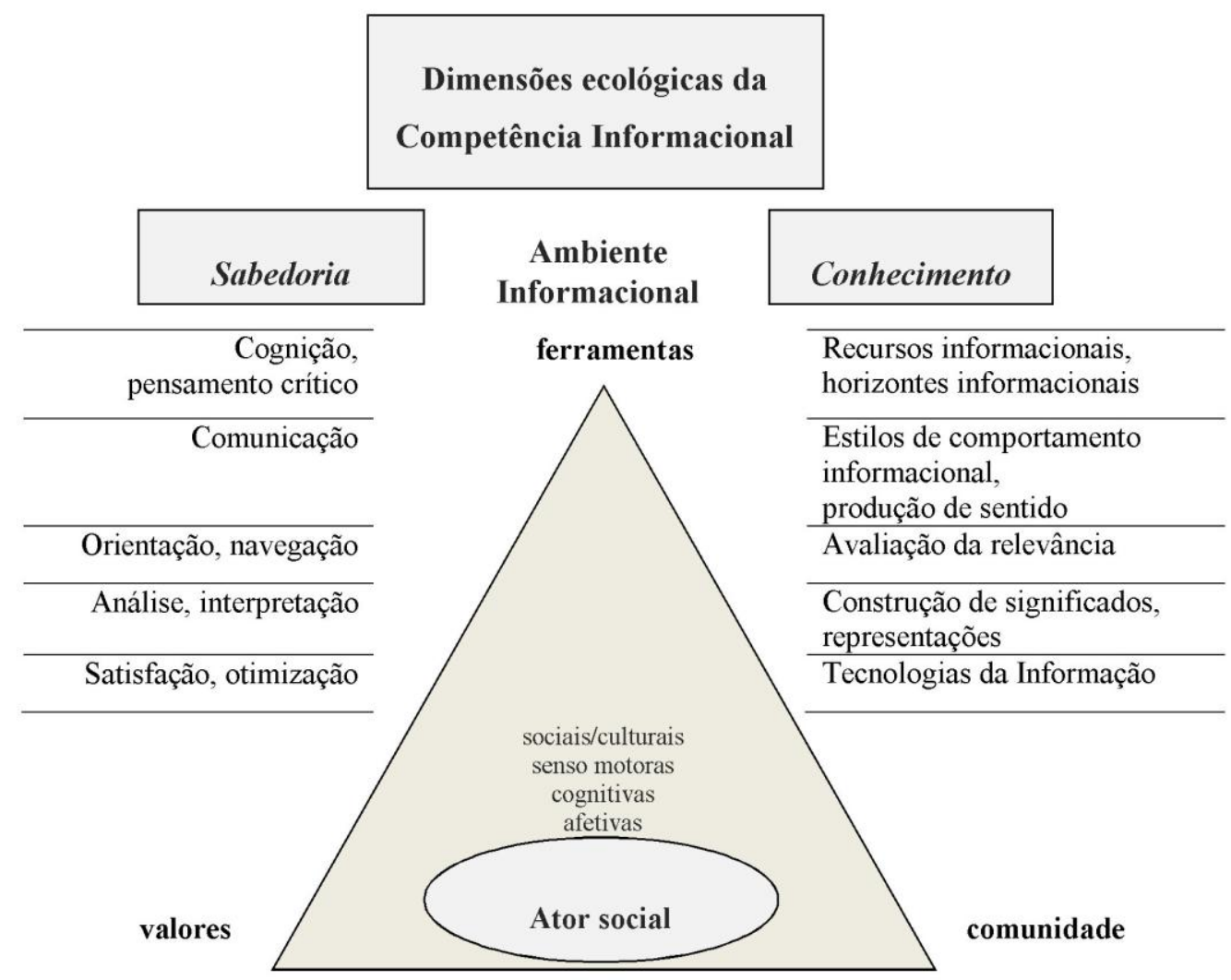

Fonte: Adaptação de Steinerová (2010).

Assim, a informação na ecologia da competência em informação pode ser determinada como uma forma de existência da informação no ambiente de informação. Não é o volume de informações ou imediatismo da entrega que 
importa, mas ferramentas para suporte e para dar sentido e transformar a informação em conhecimento.

Dimensões ecológicas da competência em informação podem ser melhores exploradas se as seguintes perguntas forem feitas: Como fornecer contextos informacionais para a tomada de sentido? Como desenvolver a competência em informação, aprendendo a conhecer e a aprender a fazer? Quais as ferramentas digitais podem auxiliar no uso de informação de forma mais eficiente? e Quais são as conexões entre a competência em informação e a aprendizagem em comunidades (aprender a viver juntos e aprender a ser)?

A Ecologia da Informação auxilia a identificar os fatores que tem um impacto sobre o ambiente de informação e ferramentas para eliminar a sobrecarga e os riscos do uso da informação. Dimensões ecológicas são determinadas em nível micro (cognitiva, individual, afetiva, habilidades sensomotoras na construção de horizontes e caminhos de informação) e em nível macro (fontes de informação, sistemas, ambientes). Nas interações entre estes níveis e fatores podem ocorrer continuidade e descontinuidade de informação sobre o desenvolvimento da competência em informação. Isto inclui as comunicações formais e informais, a colaboração, o controle de qualidade, a sobrecarga de informações, a criatividade e a ética, a consciência e a segurança jurídica, a produção de conhecimento e as normas, as quais também são caracterizadas como dimensões ecológicas de competência em informação.

Para Steinerová (2010), o conceito de Ecologia da Informação contribui para a competência em informação pela visão holística no processamento de informações e em seu uso. Teorias ecológicas da informação dão lugar de destaque ao comportamento dos seres humanos e coloca estes como centro de ambientes de informação. Essa visão também coloca a competência em informação em sintonia com a integração de inovações tecnológicas e processos de informação social. Enquanto em conceitos tecnológicos pessoas tiveram de se adaptar às tecnologias, conceitos ecológicos da tecnologia são adaptados às necessidades de informação e tornam-se parte da competência em informação. 


\section{Considerações finais}

O caminho percorrido neste estudo constituiu-se na construção do conhecimento sobre o fenômeno da Gestão da Informação, buscando mostrar uma inovação conceitual na Ciência da Informação, ao associar a competência em informação à abordagem da Ecologia da Informação, com vistas à descrição dos componentes do ambiente informacional de organizações e dos componentes do ambiente externo, ou seja, a influência destes componentes sob o uso da informação e vice-versa.

Para a melhoria do ambiente informacional, faz-se necessário dar atenção ao lado humano no uso da informação, colocando pessoas no centro do gerenciamento informacional (DAVENPORT, 1998). Ainda, com o propósito de buscar o aprimoramento da Gestão da Informação nas organizações, algumas ações podem ser percorridas com base no modelo ecológico proposto por Davenport (1998).

Em relação ao ambiente informacional: deixar claro o que se quer com a informação por meio de uma declaração de princípios informacionais; reunir e analisar as informações mais importantes na organização e atuar a partir delas; conscientizar os gestores do poder que têm sobre a informação e o gerenciamento do seu uso, atuando, em conjunto, sobre questões mais amplas; instruir comportamentos desejáveis, estabelecendo, divulgando e estimulando comportamentos que melhorem o ambiente informacional; ver em cada indivíduo um membro da equipe informacional e criar uma estrutura de gerenciamento de unidades informacionais; estruturar os processos informacionais, a fim de aperfeiçoá-los ou mudá-los; e desenvolver um guia para estruturar e localizar a informação dentro da organização, com foco no comportamento e na motivação dos usuários.

Para o ambiente organizacional sugere-se: aproveitar o ambiente administrativo, por meio dos objetivos organizacionais, processos, estrutura administrativa, cultura organizacional e recursos humanos, auxiliando nas transformações necessárias ao uso da informação; atualizar e manter tecnologias 
de fácil compreensão para o usuário; e aproximar os indivíduos que precisam trocar informação, facilitando o uso e o compartilhamento de informações.

Já para o ambiente externo, propõe-se absorver organizacionalmente as condições da sociedade e das políticas públicas; monitorar novas tecnologias, decompondo-as em tipos específicos segundo a relação com os objetivos do trabalho; atualizar-se em relação às demandas externas; e manter um quadro de pessoal que não se acomode com o ambiente informacional interno.

Desenvolver-se sob o foco das dimensões - conforme apresentado neste trabalho -, com meios adequados, exige larga competência administrativa, como também é difícil decidir por onde começar, e que sequência de atividades estabelecer. Sugere-se, então, iniciar por dois componentes: a equipe de gerenciamento informacional e o mapeamento da informação. Pela equipe informacional, para definir os responsáveis por administrar as transformações; e pelo mapeamento, para melhorar a maneira do acesso à informação; o que também contribui para o fortalecimento do conceito de gerenciamento informacional.

Espera-se que os resultados deste estudo possam servir como orientação para a Gestão da Informação nas organizações. Considerando que o tema da Gestão da Informação não se finda aqui, espera-se que esta pesquisa sirva como motivação para novos estudos interdisciplinares, envolvendo a gestão da informação, a tecnologia da informação, a comunicação, a educação, a psicologia e a sociologia, áreas que ainda podem ser mais trabalhadas em conjunto. Nesse sentido, sugerem-se novos estudos em Gestão da Informação sob o foco de abordagens mais comportamentais e menos tecnológicas.

Vários modelos de Ecologia da Informação e de competência em informação têm sido desenvolvidos até o momento. Esses modelos representam processos cognitivos e habilidades necessárias para o uso da informação. Considera-se que, sob a perspectiva deste trabalho, a integração de estilos de comportamentos de informação e de avaliação da relevância incluem principalmente questões de ordem semântica, visual, comportamental e também dimensões sociais. 
A abordagem proposta neste estudo preenche uma lacuna na integração da investigação sobre a relevância da informação e os conceitos de competência em informação, no sentido de novas formas de comunicação em grupos de curto prazo (por exemplo, em sala de aula, na organização) ou em grupos de longo prazo (família, amigos).

Hábitos de informação, principalmente no ambiente eletrônico, indicam que simplicidade, atratividade, imagens e imediatismo dominam o uso da informação. Essa é a razão por que os modelos ecológicos de competência em informação enfatizam a navegação, a personalização e a visualização. Ao serem orientados, os indivíduos modificam o modo de analisar a informação, seu estilo de comportamento quanto ao uso da informação e as habilidades práticas de processamento de informações. Isso favorece o desenvolvimento e as adaptações de horizontes de informação dos usuários e das suas estratégias em ambientes informacionais.

Os benefícios de dimensões ecológicas da competência em informação residem em "saber lidar" com as relações entre ambientes de informação interno e externo. O modelo proposto por Steinerová (2010) pode apoiar projetos de bibliotecas digitais que utilizam a aprendizagem baseada em recursos, orientada para o problema e a aprendizagem orientada para o projeto, além da aprendizagem multimídia, e-learning, etc.

Portanto, compreender dimensões ecológicas da competência em informação pode ser benéfico para o desenvolvimento desta metacompetência e das estratégias de ensino e de aprendizagem informacional em variados grupos de indivíduos e em diversos níveis e situações, sejam estes organizacionais ou em ambientes universitários. ${ }^{1}$ 


\section{Referências}

AMARAL, Luis Alfredo Martins do. Praxis: um referencial para o planejamento de sistemas de informação. 1994. $251 \mathrm{f}$. Tese (Doutorado) Universidade do Minho, Braga, 1994. Disponível em:

<https://repositorium.sdum.uminho.pt/retrieve/301/PRAXIS_Amaral.pdf>. Acesso em: 02 nov. 2014.

ASSOCIATION OF COLLEGE \& RESEARCH LIBRARIES. Presidential committee on information literacy: final report. Washington: ACRL, 1989. Disponível em: <http://www.ala.org/acrl/publications/whitepapers/presidentiall>. Acesso em: 23 ago. 2014.

BEAL, Adriana. Gestão estratégica da informação: como transformar a informação e a tecnologia da informação em fatores de crescimento e de alto desempenho nas organizações. São Paulo: Atlas, 2004.

BUNDY, Alan (Ed.). Australian and New Zealand information literacy framework: principles, standards and practice. 2nd ed. Adelaide: Australian and New Zealand Institute for Information Literacy, 2004.

CHOO, Chun Wei. Gestão de informação para a organização inteligente: a arte de explorar o meio ambiente. Lisboa: Caminho, 2003.

DAVENPORT, Thomas H. Ecologia da informação: por que só a tecnologia não basta para o sucesso na era da informação. São Paulo: Futura, 1998.

DUDZIAK, Elisabeth Adriana. Competência informacional: análise evolucionária das tendências da pesquisa e produtividade científica em âmbito mundial.

Informação \& Informação, Londrina, v. 15, n. 2, p. 1-22, jul./dez. 2010. Disponível em:

<http://www.uel.br/revistas/uel/index.php/informacao/article/viewFile/7045/699 4>. Acesso em: 23 ago. 2014.

DUDZIAK, Elisabeth Adriana. Information literacy: princípios, filosofia e prática. Ciência da Informação, Brasília, v. 32, n. 1, p. 23-35, jan./abr. 2003. Disponível em:

<http://www.scielo.br/scielo.php?script=sci arttext\&pid=S0100$19652003000100003 \& \operatorname{lng}=p t \& n r m=i s o \& \operatorname{lng}=p t>$. Acesso em: 23 ago. 2014.

FREIRE, Gustavo Henrique de Araújo. Construção participativa de instrumento de política pública para gestão e acesso à informação. Perspectivas em Ciência da Informação, Belo Horizonte, v. 13, n. 3, p. 195-207, set./dez. 2008. Disponível em: <http://portaldeperiodicos.eci.ufmg.br/index.php/pci/article/view/224>. Acesso em: 23 ago. 2014. 
GEWANDSZNAJDER, Flavio. A influência da gestão da informação no processo decisório da previdência social brasileira: um estudo exploratório. 2005. 145 f. Dissertação (Mestrado em Administração de Empresas) - Programa de Pós-Graduação em Administração de Empresas, Pontifícia Universidade Católica do Rio de Janeiro, Rio de Janeiro, 2005.

GIL, Antonio Carlos. Como elaborar projetos de pesquisa. 3. ed. São Paulo: Atlas, 1991.

GODOY, Arilda Schmidt. Introdução à pesquisa qualitativa e suas possibilidades. Revista de Administração de Empresas, São Paulo, v. 35, n. 2, p. 57-63, mar./abr. 1995. Disponível em:

<http://www.scielo.br/scielo.php?script=sci_arttext\&pid=S003475901995000200008>. Acesso em: 23 ago. 2014.

GONZÁLEZ DE GÓMEZ, Maria Nélida de. Da política de informação ao papel da informação na política contemporânea. Revista Internacional de Estudos Políticos, Rio de Janeiro, v. 1, n. 1, p. 57-93, abr. 1999.

HEEMANN, Christiane. Teoria da atividade e o ensino de línguas. In: ENCONTRO DO CÍRCULO DE ESTUDOS LINGUÍSTICOS DO SUL, 6 , 2004, Florianópolis, SC. MIOTO, Carlos et. al. (Orgs.). Anais... Florianópolis, Celsul, 2006. p. 1-09. Disponível em <http://www.celsul.org.br/Encontros/06/Individuais/170.pdf >. Acesso em 17 mar. 2016.

HENRIQUE, Luiz Cláudio Junqueira; BARBOSA, Ricardo Rodrigues. Busca da informação em marketing: a perspectiva da ciência da informação. Revista de Administração de Empresas, São Paulo, v. 49, n. 2, p. 221-233, abr./jun. 2009. Disponível em:

<http://www.scielo.br/scielo.php?script=sci_arttext\&pid=S003475902009000200008>. Acesso em: 23 ago. 2014.

MCGEE, James; PRUSAK, Laurence. Gerenciamento estratégico da informação: aumente a competitividade e a eficiência de sua empresa utilizando a informação como uma ferramenta estratégica. 7. ed. Rio de Janeiro: Campus, 1994.

OLIVEIRA, Joelma de Souza Passos de. A gestão da informação como suporte ao processo de tomada de decisão em uma instituição pública de ensino superior: um estudo de caso. 2010. 163 f. Dissertação (Mestrado em Ciência, Gestão e Tecnologia da Informação) - Setor de Ciências Sociais Aplicadas, Universidade Federal do Paraná, Curitiba, 2010.

RAMOS, Rosana Guedes Cordeiro; ALCANTARA, Alexandre; MORESI, Eduardo Amadeu Dutra. Construindo uma arquitetura da informação baseada em metadados. [S.1.: s.n.], 2011. Disponível em: 
$\langle$ http://grise.upm.es/rearviewmirror/conferencias/jiisic04/Papers/59.pdf $>$.

Acesso em: 02 nov. 2014.

REZENDE, Denis Alcides; ABREU, Aline França de. Tecnologia da informação: aplicada a sistemas de informação empresariais. 8. ed. São Paulo: Atlas, 2011.

RIOS, Terezinha Azerêdo. A presença da filosofia e da ética no contexto profissional. Organicom, ano 5, n. 8, p. 79-88, 2008. Disponível em: <http://revistaorganicom.org.br/sistema/index.php/organicom/article/viewFile/1 45/245>. Acesso em: 02 nov. 2014.

SILVA, Elizabeth Coelho Rosa e. A gestão da informação na Universidade Federal de Santa Catarina sob a abordagem da ecologia da informação. 2012. 214 f. Dissertação (Mestrado Profissional em Administração Universitária) - Programa de Pós-Graduação em Administração Universitária, Universidade Federal de Santa Catarina, Florianópolis, 2012. Disponível em: $<$ https://repositorio.ufsc.br/bitstream/handle/123456789/100943/310999.pdf?seq uence $=1 \&$ is Allowed $=y>$. Acesso em: 26 out. 2015.

SINGH, Jagtar. Sense-making: information literacy for lifelong learning and knowledge management. Journal of Library and Information Technology, v. 28, n. 2, p. 13-17, Mar. 2008. Disponível em:

<http://publications.drdo.gov.in/ojs/index.php/djlit/article/view/161/74>. Acesso em: 20 abr. 2012.

SORDI, José Osvaldo de. Tecnologia da informação aplicada aos negócios. São Paulo: Atlas, 2003.

STEINEROVÁ, Jela. Ecological dimensions of information literacy.

Information Research, v. 15, n. 1, Mar. 2010. Disponível em: <http://www.informationr.net/ir/15-4/colis719.html>. Acesso em: 6 maio 2014.

VITORINO, Elizete Vieira; PIANTOLA, Daniela. Competência informacional: bases históricas e conceituais: construindo significados. Ciência da Informação, Brasília, DF, v.38, n.3, p.130-141, set./dez., 2009. Disponível em: <http://www.scielo.br/pdf/ci/v38n3/v38n3a09.pdf>. Acesso em: 04 fev. 2016.

VITORINO, Elizete Vieira; PIANTOLA, Daniela. Dimensões da competência informacional. Ciência da Informação, Brasília, DF, v.40, n.1, p.99-110, jan./abr., 2011. Disponível em: <http://revista.ibict.br/ciinf/index.php/ciinf/article/view/1918/1397>. Acesso em: 04 fev. 2016.

URIBE TIRADO, Alejandro; PENAGOS, Leonardo Machett's. Estado del arte de la alfabetización informacional en Colombia 2010. [S.l.: s.n.], 2011.

Disponível em: 
$<$ http://eprints.rclis.org/15465/1/Alfabetizaci\%C3\%B3n\%20Informacional\%20e n\%20Colombia.pdf $>$. Acesso em: 23 ago. 2014.

\title{
ZURKOWSKI, Paul G. The information service environment relationships and
}

priorities. Related Paper no 5. Washington: National Program for Library and Information Services, 1974. Disponível em:

<http://files.eric.ed.gov/fulltext/ED100391.pdf>. Acesso em: 23 ago. 2014.

\section{Information Management under Ecology approach: possibilities to information literacy}

\begin{abstract}
The existence of today's organizations takes place in an environment of interrelations that are in a constant state of transformation. In this context, the value of information is crucial for organizations to predict, understand and respond to the environmental changes. This paper presents the Information Management under the approach of the Ecology of Information, classified as a bibliography research, which allows the recovery of accumulated scientific knowledge on Information Management, Ecology of Information and Informational Competence, from material produced mostly from books and scientific articles. It also examines the relations between Informational Competence and Ecology of Information, both concerning the conceptual innovation in Information Science. The results point to the integration of diversified informational components, which shows the need to assimilate the information under a perspective less technological and more critical and reflective, that puts people at the center of informational management, in order to achieve the development of Informational Competence.
\end{abstract}

Keywords: Informational Management. Ecology of Information. Informational Competence.

Recebido: 12/05/2015

Aceito: $11 / 11 / 2015$ 
A Gestão da Informação sob a abordagem da Ecologia: possibilidades à competência em informação

Elizabeth Coelho Rosa e Silva, Elizete Vieira Vitorino

\footnotetext{
${ }^{1}$ Para outros resultados desta pesquisa, consultar Silva (2012).
} 